\title{
Expression and activity of Rac1 is negatively affected in the dehydroepiandrosterone induced polycystic ovary of mouse
}

Vineet Kumar Maurya ${ }^{1}$, Chadchan Sangappa ${ }^{1}$, Vijay Kumar ${ }^{1}$, Sahil Mahfooz ${ }^{1}$, Archana Singh ${ }^{1}$, Singh Rajender ${ }^{2}$ and Rajesh Kumar Jha ${ }^{1^{*}}$

\begin{abstract}
Background: Polycystic ovarian syndrome (PCOS) is characterized by the presence of multiple follicular cysts, giving rise to infertility due to anovulation. This syndrome affects about $10 \%$ of women, worldwide. The exact molecular mechanism leading to PCOS remains obscure. RhoGTPase has been associated with oogenesis, but its role in PCOS remains unexplored. Therefore, we attempted to elucidate the Vav-Rac1 signaling in PCOS mice model.

Methods: We generated a PCOS mice model by injecting dehydroepiandrosterone (DHEA) for a period of 20 days. The expression levels of Rac1, pRac1, Vav, pVav and Caveolin1 were analyzed by employing immuno-blotting and densitometry. The association between Vav and Rac1 proteins were studied by immuno-precipitation. Furthermore, we analyzed the activity of Rac1 and levels of inhibin B and 17ß-estradiol in ovary using biochemical assays.

Results: The presence of multiple follicular cysts in ovary were confirmed by histology. The activity of Rac1 (GTP bound state) was significantly reduced in the PCOS ovary. Similarly, the expression levels of Rac1 and its phosphorylated form (pRac1) were decreased in PCOS in comparison to the sham ovary. The expression level and activity (phosphorylated form) of guanine nucleotide exchanger of Rac1, Vav, was moderately down-regulated. We observed comparatively increased expressions of Caveolin1, 17ß-estradiol, and inhibin B in the polycystic ovary.

Conclusion: We conclude that hyperandrogenization (PCOS) by DHEA diminishes ovarian Rac1 and Vav expression and activity along with an increase in expression of Caveolin1. This is accompanied by an increase in the intra-ovarian level of '17 $\beta$-estradiol and inhibin B.
\end{abstract}

Keywords: Polycystic ovary, Dehydroepiandrosterone, Rac1, Estradiol, Vav, Caveolin1

\section{Introduction}

The pool of primordial follicles in the ovary supply eggs for the entire reproductive life in mammals. To maintain fertility for the whole reproductive period, the primordial follicles are reserved in a quiescent state for regulated successive ovulation [1-3]. Primordial follicles are recruited from the reserve of dormant follicles into the pool of growing follicles through their activation process during which they undergo a series of developments [3].

\footnotetext{
* Correspondence: rajesh_jha@cdri.res.in

'Division of Endocrinology, Life Science North 111B/101, CSIR-Central Drug Research Institute, B.S. 10/1, Sector-10, Jankipuram Extension, Sitapur Road, Lucknow 226031, India

Full list of author information is available at the end of the article
}

Polycystic ovarian syndrome (PCOS) is characterized by anovulation and in the presence of multiple small cysts typically arranged in the periphery of one or both ovaries. PCOS can affect $5-10 \%$ of women during their reproductive age and contributes to this etiology in about $10 \%$ of the infertile women [4-6]. This disorder is considered to be a manifestation of the disturbance in the endocrine system, which causes secondary disorders contributing to female infertility [7]. The most commonly seen endocrine disturbance is hyperandrogenism accompanied by chronic oligo or anovulation [8]. The hypothalamic-pituitary synchrony is disrupted that increases pulsatile secretion of gonadotropin, disturbs oocyte-granulosa cell interaction, enhances 
ovarian androgen production and causes excess insulin production and that leads to insulin resistance [9]. As a result, metabolic syndrome (MS) is seen in about $46 \%$ of the PCOS cases [10].

However, the intra-ovarian pathophysiology of PCOS is not yet explicit at cellular and molecular levels. The available data till date is insufficient to precisely delineate the intra-ovarian pathway that contributes to the development of this disorder. Therefore, we need further investigations to pinpoint the correct mechanism leading to the development of this disorder. The G-protein family member, Ras, has already been shown to participate in the pathophysiology of PCOS [11]. Another member of Rho family protein, Rac, is involved in gonad formation [12] and acts downstream to integrin signaling [13]. Its expression/activity is controlled by estrogen [14]. Rho guanine dissociation inhibitor (RhoGDI) antagonizes Rac1 and keeps it in the inactive state $[15,16]$. The Rho assists in actin dynamics through cofilin regulation by Luteinizing hormone signaling [17] in the granulosa cells [18]. Furthermore, Rac modulates cell cycle [19], which is activated by guanine exchange factor Vav [20,21]. Further, it is reported that Rac gets phosphorylated in the process of its activation [22]. Similarly, Vav also gets phosphorylated before it executes Rac activation [23,24]. Looking at the role of Rac/Vav signaling in ovarian physiology, we designed the present study to analyze expression and activity of Rac1 and Vav proteins in the ovary of a mice model of PCOS.

\section{Materials and methods Reagents}

Dehydroisoandrosterone 3'-sulphate (cat no. D5297), hematoxylin (cat no. H3136), anti-beta-actin (cat no. A2668) and goat anti-Mouse IgG ( $\gamma$-chain specific)-HRP (cat no. A3673) were purchased from Sigma Aldrich Inc., St Louis, MO, USA. Immobilon-P PVDF membrane $(0.45 \mu \mathrm{m})$, ECL reagent kits (cat no. WBKLS0500), ProteinA-Agarose suspension (cat no. IP02) and goat anti-rabbitHRP IgG (cat no.621140380011730) were procured from Merck-Millipore, Cedex, France. Other primary antibodies against phospho-Vav (Y174) (cat no. ab47282), phosphoRac1/Cdc42 (S71) (cat no. ab5482) and Rac1 (cat no. ab33186) were purchased from Abcam, Cambridge, MA, USA. Anti-Vav (cat no. sc132) and anti-Caveolin1 (cat no. sc894) were purchased from Santa Cruz Biotechnology, CA, USA. Non-fat milk (cat no.170-6404) and precision plus protein standard marker (cat no. 161-0374) were obtained from Bio-Rad Lab., Inc., Hercules, CA., USA. Protein assay kit (cat no. 23225) was procured from ThermoScientific, Rockford, USA. The G-LISA Rac1 activation assay Biochem Kit (cat no. BK128) was purchased from Cytoskeleton, Denver, CO, USA. Inhibin B Enzyme Immunoassay kit (cat no. EIA-INB-1) was purchased from RayBiotech, Inc., Norcross, GA, USA. $17 \beta$-estradiol assay kit (cat no. ADI-900-008) was obtained from Enzo Life Science, Inc., Farmingdale New York, USA.

\section{PCOS experimental animal model}

The murine model of PCOS was developed by administering Mus musculus (strain C57/BL6) with dehydroisoandrosterone (DHEA). PCOS was induced in 22 days old mice (12 gm) by injecting DHEA (6 mg/100gm body weight; dissolved in $0.01 \mathrm{ml} \mathrm{95 \%}$ ethanol, which was further diluted with corn oil) subcutaneously for 20 consecutive days as described previously [25-28]. The model is characterized by higher levels of serum testosterone, androstenedione and 5-alpha-dihydrotestosterone similar to that seen in PCOS patients. Previous studies have established that the DHEA-PCOS murine model represents some of the salient features of human PCOS, such as hyperandrogenism, abnormal maturation of ovarian follicles and anovulation [26,27,29-31]. We administered corn oil along with 95\% ethanol in the control (sham) group. Animal usage and the protocols were duly approved by the Institutional Animal Ethics Committee of the CDRI, Lucknow, India. The animals were housed in a temperature-controlled facility $\left(25 \pm 1^{\circ} \mathrm{C}\right)$ with required illumination $(12 \mathrm{~h}$ light and $12 \mathrm{~h}$ dark). Free access to food and water were provided to the animals. At the end of the experiments, animals were sacrificed by cervical dislocation followed by excision of ovaries, which were snap frozen at $-80^{\circ} \mathrm{C}$ until further use. Each treatment/control group consisted of six animals.

\section{Ovarian tissue histology and staining}

To evaluate the histological alteration in the ovary, DHEA treated and sham/control ovaries were dissected and allowed to fix overnight at $4^{\circ} \mathrm{C}$ in $4 \%$ paraformaldehyde (PFA)-phosphate buffered saline (PBS). On subsequent day, tissue samples were kept in the tissue cassette and dehydrated using acetone (two times for $30 \mathrm{~min}$ each), acetone + benzene (1:1, $30 \mathrm{~min})$ and cleared in benzene (two times for $30 \mathrm{~min}$ each). Subsequently, the tissues were removed and embedded in paraffin wax (Fisher Scientific, Rockford, USA) for $4 \mathrm{~h}$ at $65^{\circ} \mathrm{C}$. This was followed by preparation of tissue paraffin moulds.

Embedded ovarian tissues were sectioned $(5 \mu \mathrm{m})$ using microtome (Leica Biosystem, Germany) and mounted on poly-L-lysine (Sigma-Aldrich, MO, USA) coated glass slides. Sections were deparaffinized with two changes of xylene (10 min each) and rehydrated with subsequent changes of absolute alcohol (two times, five min each), 95\% (two min) and 70\% alcohol (two min). Sections were briefly washed (three times) and stained with hematoxylin solution for eight min. After staining, sections were again washed and kept for blue color development in 1.5\% ammonium hydroxide (30\% stock) for 30 sec. The tissue section mounted slides were washed in distilled 
water for five min, rinsed in 95\% alcohol (10 repeats) and counterstained with $0.5 \%$ eosin for $30 \mathrm{sec}$. This was followed by dehydration through $95 \%$ and absolute alcohol two times for five min each. Finally, the slides were cleared in xylene two times for five min each and mounted with DPX mountant. The tissue sections were imaged through Inverted Phase Contrast Microscope (TS100-F, Nikon, Japan) using 5.2 megapixels digital camera (DS-Fi2-U3, Nikon, Japan).

\section{Ovarian protein extract preparation}

After excision, the ovaries were processed for total (cytosol + plasma membrane) protein extract preparation. The ovarian tissue was minced and homogenized in a buffer containing $100 \mathrm{mM} \mathrm{KCl}, 3 \mathrm{mM} \mathrm{NaCl}, 3.5 \mathrm{mM}$ $\mathrm{MgCl}_{2}, 10 \mathrm{mM}$ PIPES, $1.5 \mathrm{mM}$ EGTA, $1 \mathrm{mM}$ PMSF, $50 \mathrm{~g} / \mathrm{ml}$, phosphatase, and protease inhibitors ( $\mathrm{pH}-7.4$ ) [32]. The tissue homogenate was centrifuged at $200 \times \mathrm{g}$ for $10 \mathrm{~min}$ at $4^{\circ} \mathrm{C}$ to pellet-out unbroken cells and tissue debris. Later, the mitochondrial fraction was removed by centrifuging the preparation at $12,000 \times \mathrm{g}$. The concentration of protein was estimated using Pierce BCA protein assay kit as per the manufacturer's instructions. Suitable concentration $(20 \mu \mathrm{g})$ of protein extract was prepared for down-stream purposes.

\section{Rac1 activity assay}

The activity of Rac1 (GTP bound form) was assayed in the ovarian protein extract using G-LISA Rac1 activation assay Biochem Kit, as per the manufacturer's instructions and that is already validated [33]. Briefly, a total of $50 \mu \mathrm{g}$ protein extract was added to each corresponding well pre-coated with Rac-GTP-binding protein. This was incubated at $4^{\circ} \mathrm{C}$ for $30 \mathrm{~min}$ followed by successive incubation with $50 \mu \mathrm{l}$ of anti-Rac1 for $45 \mathrm{~min}$. Later, secondary antibody conjugated with $\operatorname{HRP}(50 \mu \mathrm{l})$ was incubated for 45 minutes. Subsequently, $50 \mu \mathrm{l}$ of HRP detection reagent was added to each well, followed by incubation for another $20 \mathrm{~min}$. The reaction was stopped by the addition of $50 \mu \mathrm{l}$ of HRP stop solution and the absorbance was recorded at $490 \mathrm{~nm}$.

\section{Inhibin B assay}

The level of inhibin $B$ was determined in the ovarian protein extract using RayBio Inhibin B Enzyme Immunoassay kit as per the manufacturer's instructions. We added $100 \mu \mathrm{l}$ of inhibin B antibody in each well of micro-plate, which was pre-coated with anti-rabbit antibody. The plate was incubated overnight at $4^{\circ} \mathrm{C}$ with gentle shaking. This was followed by the addition of $100 \mu \mathrm{l}$ of protein sample to each well and incubation overnight at $4^{\circ} \mathrm{C}$. HRP-Streptavidin was added followed by incubation at room temperature for $45 \mathrm{~min}$. Subsequently, $100 \mu \mathrm{l}$ of 5'-tetramethylbenzimide (TMB) was added as HRP detection reagent and incubated at room temperature in dark for $30 \mathrm{~min}$. The reaction was terminated by adding $50 \mu \mathrm{l}$ stop solution and absorbance was recorded at $450 \mathrm{~nm}$

\section{$17 \beta$-estradiol hormone estimation}

The assay was performed as per instructions provided by the manufacturer. A total of $40 \mu \mathrm{g}(100 \mu \mathrm{l})$ ovarian protein $(n=4$; sample pooled from 10 animals to form 4 replicate in each group) was used for this assay. The standard of $17 \beta$-estradiol was prepared by the addition of $100 \mu \mathrm{l}$ standards $(30,000 \mathrm{pg} / \mathrm{ml}, 7,500 \mathrm{pg} / \mathrm{ml}, 1,875 \mathrm{pg} / \mathrm{ml}$, $468.8 \mathrm{pg} / \mathrm{ml}, 117.2 \mathrm{pg} / \mathrm{ml}$ and $29.3 \mathrm{pg} / \mathrm{ml}$ ) and assay buffer3 $(50 \mu \mathrm{l})$ into respective standard wells, whereas the standard diluent $(100 \mu \mathrm{l})$ was added to well $\mathrm{B}_{0}$ (maximum binding well). The NSB (negative control) received standard diluents $(100 \mu \mathrm{l})$, assay buffer3 $(50 \mu \mathrm{l})$ and conjugate (phosphatase conjugated with $17 \beta$-estradiol) $(50 \mu \mathrm{l})$. Blank was prepared by adding only substrate $(200 \mu \mathrm{l})$ and stop solution $(50 \mu \mathrm{l})$. Next, we added $50 \mu \mathrm{l}$ of conjugate in all the wells except blank. Antibody against $17 \beta$-estradiol $(50 \mu \mathrm{l})$ was added in wells $\mathrm{B}_{0}$, standard, and samples only followed by incubation of plate at room-temperature (RT) for $2 \mathrm{~h}$. The unbound/excess content was decanted and micro-plate was washed thrice with $400 \mu \mathrm{l}$ of wash buffer by gentle tapping on paper towel. Thereafter, a substrate (p-nitrophenyl phosphate; $200 \mu \mathrm{l}$ ) was added in each well followed by incubation at RT for 45 min. Finally, a stop solution (trisodium phosphate; $50 \mu \mathrm{l}$ ) was added to each well and micro-plate was read at $405 \mathrm{~nm}$ using micro-plate reader (SPECTRO star Nano, BMG LABTECH, GmbH, Germany). The graph was plotted with absorbance versus standards (17ß-estradiol; pg/ml) after subtraction of NSB values. The concentration of $17 \beta$-estradiol was calculated based on the standard curve.

\section{Co-immuno-precipitation assay}

The ovarian protein lysate (100 $\mu \mathrm{g}$, sham group) from each replicate was immuno-precipitated by incubation with anti-Vav overnight at $4^{\circ} \mathrm{C}$. To collect the immune complexes, Protein-A-Agarose $(20 \mu \mathrm{l})$ was added and the lysate-bead mixture was incubated at $4^{\circ} \mathrm{C}$ under rotary agitation for $4 \mathrm{~h}$. It was followed by centrifugation at $10,000 \times \mathrm{g}$ for $10 \mathrm{~min}$ at $4^{\circ} \mathrm{C}$ and washing three times with PBS. Protein was eluted with Laemmli buffer and boiled for $5 \mathrm{~min}$. The supernatant was subjected to $12 \%$ SDS-PAGE and immuno-blotted with anti-Rac1 according to a previously described method [32].

\section{SDS-PAGE and Western blotting}

Protein sample $(20 \mu \mathrm{g})$ was denatured by boiling in Laemmli buffer [34] for $5 \mathrm{~min}$ at $95^{\circ} \mathrm{C}$ and applied on a $10-12 \%$ SDS-PAGE. The proteins resolved on the gel were 
transferred to PVDF membrane $(0.45 \mu \mathrm{m})$ in transfer buffer (20\% methanol, vol/vol; $0.19 \mathrm{M}$ glycine; $0.025 \mathrm{M}$ Tris-Base, $\mathrm{pH}=8.3$ ) [35]. The membrane was blocked with $5 \%$ non-fat milk/goat serum and incubated overnight at $4^{\circ} \mathrm{C}$ with antibodies against Rac1 (1:1000 dilution), pRac1 (1:1000 dilution), Vav (1:250 dilution), pVav (1:1000 dilution), Caveolin1 (1:1000 dilution) and beta-actin (1:6000 dilution). Thereafter, the membranes were incubated for one $\mathrm{h}$ with goat anti-rabbit IgG or goat anti-mouse IgG conjugated with Horseradish Peroxidase in a paraffin boat. Phosphate buffered saline (10 mM, $\mathrm{pH} 7.4$ containing $0.1 \%$ Tween-20, PBS-T) was used throughout the procedure. Later, the membranes were exposed to ECL reagents to visualize the protein bands and imaged through Chemi-Imager (ImageQuant LAS4000, Buckinghamshire, UK). Immuno-positive bands were analyzed by densitometry using Total Lab Quant 1D software (Nonlinear Dynamics Ltd., UK). The beta-actin blot values were used to normalize the blots value of Rac1, pRac1, Caveolin1, Vav and pVav.

\section{Statistical analysis}

All the experiments were performed in three replicates using six animals in each group. Ovarian tissue samples were pooled from two animals to form one replicates to increase the yield of protein extract. Protein band intensities were averaged and the standard error of the mean (SE) was calculated. The data were subjected to one-way ANOVA using Microsoft Excel 2007. P values less than 0.05 were considered significant for statistical inference.

\section{Results}

\section{Characterization of PCOS by histological analysis}

To demonstrate the effect of DHEA, ovaries were sectioned and stained with hematoxylin/eosin. Ovarian sections of control (sham) group showed the presence of follicles at different stages of maturation (Figure 1). Atretic, graffian and healthy follicles were clearly visible along with corpora lutea (Figure 1A). The presence of healthy oocytes in the follicles was seen (Figure $1 C$ ). In contrast, DHEA treated ovary exhibited a bit distorted morphology (Figure 1B). The numbers of antral and pre-natal follicles were increased with arrangement typically that of the polycystic ovary; however, the granulosa cells appeared to be degenerated (Figure 1D). The size of the polycystic ovary was increased, perhaps due to an increase in the number of follicles. Oocytes and corpora-lutea were not seen in the polycystic ovary.
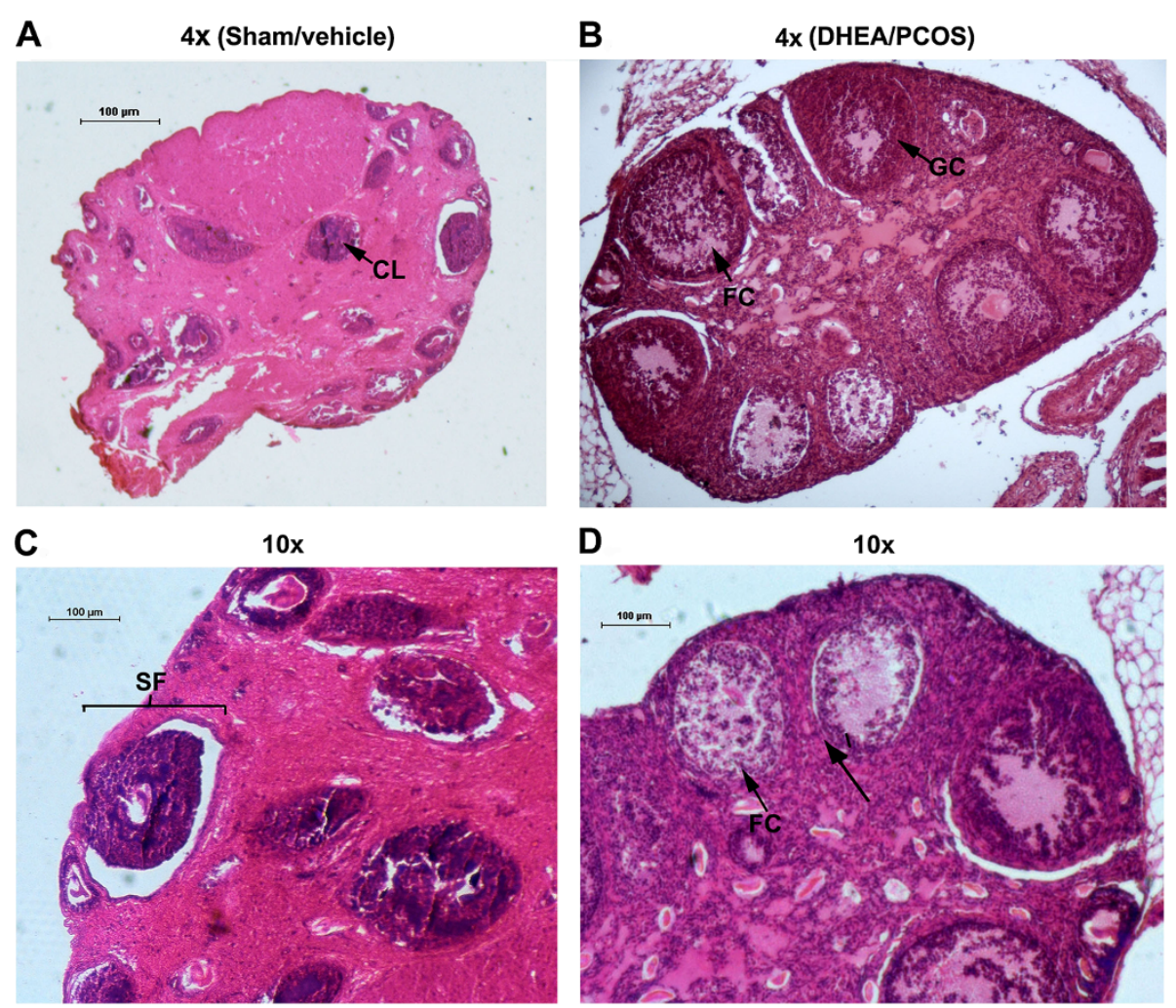

Figure 1 Morphological comparison of DHEA treated mouse ovary with its control. Sham/vehicle ovary showing (4x magnification) corpus luteum and secondary follicle (A and C), DHEA treated PCOS ovary showing (10x magnification) follicular cyst (FC) along with degenerate granulosa cells (B and D). Corpus-luteum was completely absent in polycystic ovary. 
Increased expression level of inhibin B in polycystic ovary The level of inhibin $B$ correlates with the number of follicles recruited to undergo maturation [36]. Earlier studies have reported high concentrations of serum inhibin B in polycystic ovaries [37-39]. Herein, we performed assay of inhibin $B$ in ovarian tissue protein extract to validate the pathophysiology of PCOS in our animal model. We observed a significant increase $(\mathrm{p}<0.015)$ in level of inhibin $\mathrm{B}$ in the polycystic ovaries in comparison to sham (control) ovaries. Our result showed $\sim 61 \%$ elevation in the level of inhibin $B$ (Figure 2A).

\section{Elevated level of $17 \beta$-estradiol in the PCOS ovary}

Serum level of $17 \beta$-estradiol $\left(E_{2}\right)$ indicates the development of dominant follicles [36]. Therefore, we analyzed intraovarian level of $17 \beta$-estradiol in the PCOS and control groups. We observed about three folds elevation in the level of estradiol in PCOS ovary in comparison to the control ovary $(\mathrm{p}<0.03)$ (Figure $2 \mathrm{~B})$.

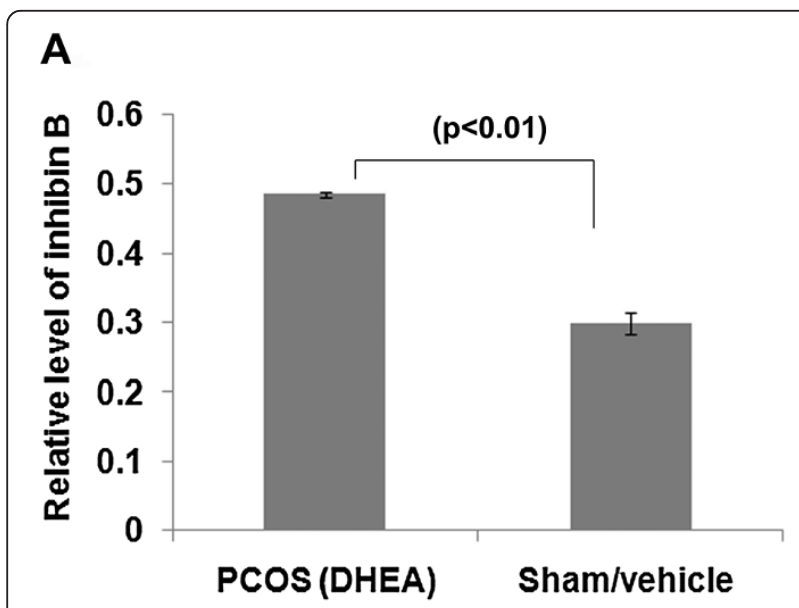

B

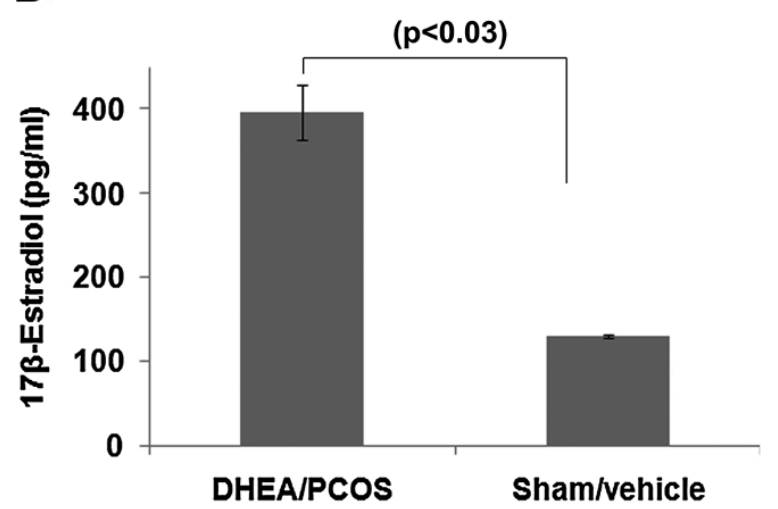

Figure 2 Level of inhibin $B$ and $17 \beta$-estradiol in sham and DHEA treated mouse ovary. The intra-ovarian level of inhibin $B(A)$ and 17- $\beta$-estradiol (B) were assessed post treatment of DHEA/sham in mouse.

\section{Down regulation of activity and expression of Rac1 in PCOS ovary}

In order to decipher the possible involvement of Rac1 signaling in PCOS, we detected the expression level of Rac1 and phosphorylated-Rac1 (S71) (pRac1) in the ovarian tissue protein extract prepared from the experimental model of PCOS. As shown in Figure 3A, compared with the sham/vehicle treated ovaries, the activity level of Rac1 was significantly decreased in the PCOS ovary. Similarly, the expression level of Rac1 protein was significantly down-regulated in DHEA treated/PCOS ovary (Figure $3 \mathrm{~B}$ and $\mathrm{C}$ ).

Further, to determine whether the activity of Rac1 in terms of its phosphorylation was affected in the DHEA treated (polycystic) ovary, the phosphorylation level of Rac1 was analyzed employing immuno-blotting. Treatment of ovary with DHEA resulted in down-regulation of pRac1 (Figure 3D and E). Thus, this domain of information suggests that DHEA/polycystic ovary may adversely affect the activity of Rac1.

\section{Association of Vav activity in PCOS ovary}

Rac1 is activated by Vav, which gets phosphorylated at tyrosine (Y) 174 [40]. To evaluate whether DHEA can also modulate of intra-ovarian activity of Rac1, we further evaluated the activity and expression level of Vav in the ovary after DHEA treatment (polycystic ovary). The activity of Vav in terms of its phosphorylation was analyzed through phosphorylation assay/Western blots (Figure 4). We found reduced expression level of total Vav in the hyper-androgenized ovary, but the difference in comparison to control was not statistically significant (Figure 4A and B). Similarly, the intensity of anti-pVav (Y174) positive band was found to be lower in PCOS in comparison to the control (sham) group $(\mathrm{p}>0.05)$ (Figure $4 \mathrm{C}$ and $\mathrm{D}$ ).

\section{Vav can interact with Rac1 in ovary}

It is well known that Vav displays guanidine exchange factor activity for Rho GTPases. We performed coimmuno-precipitation analysis to confirm the Rac1 association with Vav in the sham ovary. The Vav presence in the Vav antibody IP was confirmed by its immunoblotting (Figure 5A). As shown in Figure 5B, the immunoprecipitated protein samples by Vav antibody from the ovary of sham administered displayed immuno-positive band of Rac1, which is an indication that Rac1 interacts with Vav in the ovary.

\section{Caveolin 1 is up-regulated in PCOS ovary}

Caveolin1 is known to be an important scaffolding domain containing caveolae protein, which is involved in the regulation of several signaling cascades [41]. Since, Caveolin1 is linked to Rac1 degradation pathway, we 


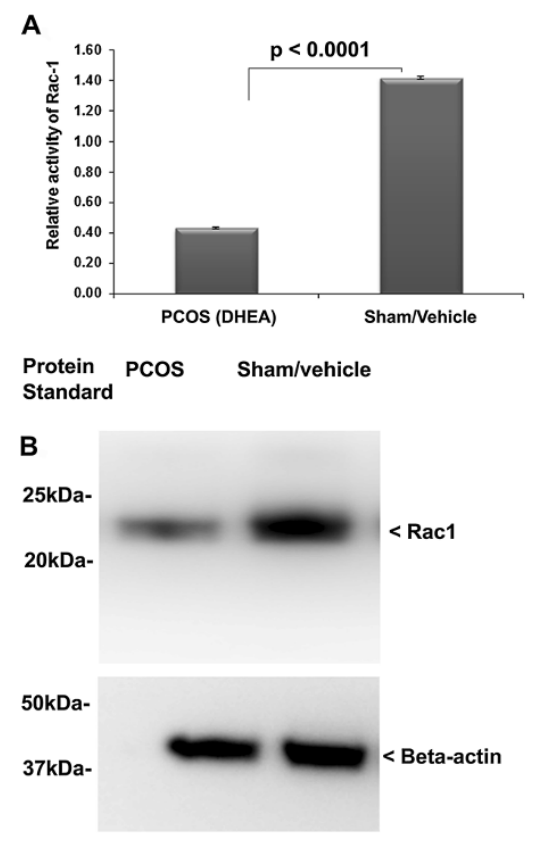

C

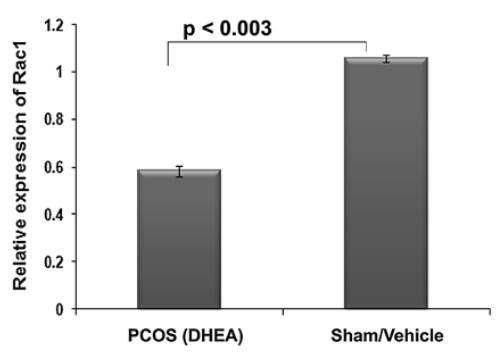

E

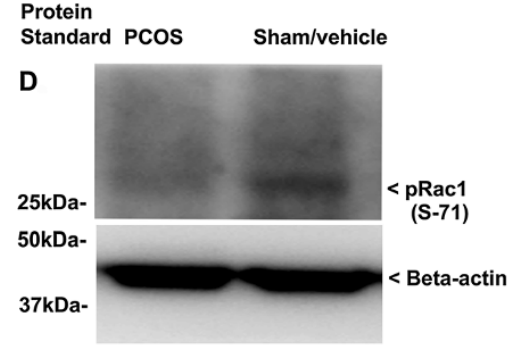

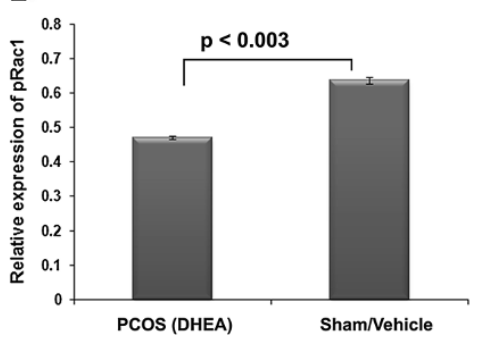

Figure 3 Determination of expression and activity of Rac1 in DHEA induced PCOS ovary. Relative activity of Rac1 was analyzed in the DHEA (PCOS) and sham treated ovary (A). Expression level analysis of Rac1 was determined by immuno-blotting and densitometry in the ovary of PCOS and sham (B and C). The activity Rac1was assayed by analysis of its phosphorylated form ( $\mathbf{D}$ and $\mathbf{E})$.

investigated the expression level of Caveolin1 in the ovarian samples. We observed a significantly increased level of Caveolin1 in PCOS ovary in comparison to the control (sham) group (Figure 6A and B).

\section{Discussion}

Intra-ovarian signaling stimulates some of the primordial follicles to grow out of a cohort. The quiescent follicles remain in the inactive stage due to inhibitory mechanism operational either within the follicles or by the signals from the ovary [3]. During the post-natal development in mice, a large number of oocytes/follicles are depleted in comparison to the growing population of follicles [42,43]. This phenomenon is similar in the humans as well [3] and depletion of the pool of primodial follicles compromises female fertility. The condition of follicle insufficiency to ovulate is not understood precisely. Previous studies have demonstrated the association of Ras and Rho signaling in the process of ovarian follicle development [43-48]. Rac1 is a member of the Ras family, making it a good candidate for investigation of its role in the regulation of follicular maturation.

The presence of multiple cysts in the ovaries are considered as a key diagnostic trait of PCOS [49-51], which was precisely mimicked in our PCOS mice model. This provided us with a platform for further biochemical and expression analysis. Our histological findings in PCOS ovary correlated well with the earlier reports showing increased ovarian size, absence of ovum and corpus-luteum in the ovaries of DHEA treated mice [52]. A relation between decrease in ovarian volume and the number of follicles with age of women with PCOS has been shown [53]. Increased level of inhibin B and $17 \beta$-estradiol in the PCOS group demonstrated elevation in the number of recruited dormant follicles in comparison to the control ovary [36]. Collectively, this confirmed a phenotype of polycystic ovary in our model system.

The estradiol negatively affects Rac1 activation [14], and in turn Rac1 regulates inhibin B [54]; however, this is not known in the ovarian tissue. Rac is a member 


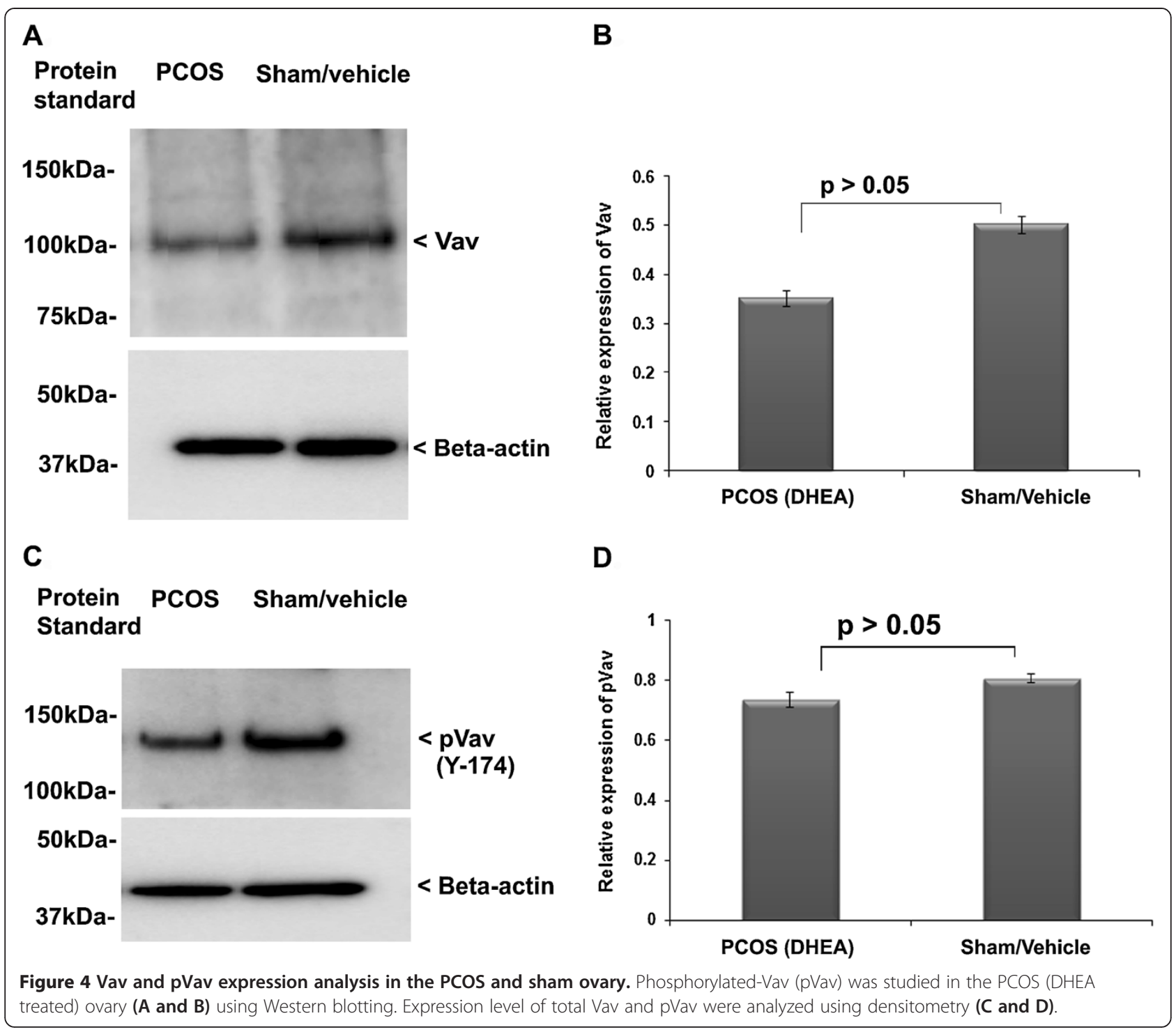

of small G-protein family (RhoGTPase) and other member of this G-protein family, Ras, has already been implicated in the pathophysiology of ovary [11]. A previous study has suggested involvement of Rac1in gonad formation [12], but its association with follicular maturation and function has not been shown. Our results suggested that expression of Rac1, pRac1 and its activity were significantly reduced in the hyperandrogenized ovary with DHEA (polycystic ovary). Activity of Rac1 was also lowered as compared to sham. It has been reported that higher production of estrogen in vascular smooth muscle cells causes down-regulation of Rac1 [14]. We observed a similar combination of elevated level of intra-ovarian 17 $\beta$-estradiol and down-regulation of Rac1 on polycystic ovary. Further to confirm the involvement of Rac1, we studied the expression level of total Vav along with its phosphorylated form, which is a known activator of Rac1 [24]. As expected, we observed a reduction in total Vav and its phosphorylated form. The association between Rac1-Vav was further confirmed by immunoprecipitation (IP), which showed Rac1 presence in the immuno-precipitates prepared using anti-Vav from sham treated group. Collectively, all the above results suggest that elevated $17 \beta$-estradiol levels might have down-regulated the activity/expression of Rac1 and Vav favoring the development of PCOS phenotype.

Several studies have also shown the interaction of Rac1 with caveolae protein, Caveolin1. Caveolin1 is known to control Rac1 protein levels by regulating ubiquitylation and degradation of activated Rac1 in an adhesion-dependent fashion [55]. The absence of Caveolin1 has been reported to increase the proliferation and anchorage-independent growth by a Rac-dependent, Erk-independent mechanism [56]. Since, there is no 
A
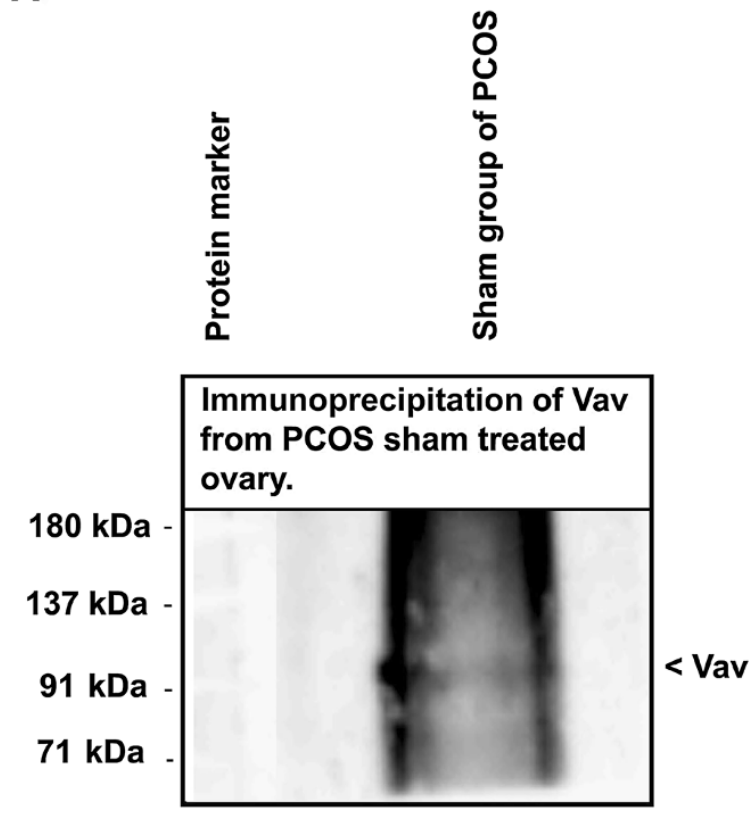

B
Immunoprecipitation of Vav from PCOS sham treated ovary.

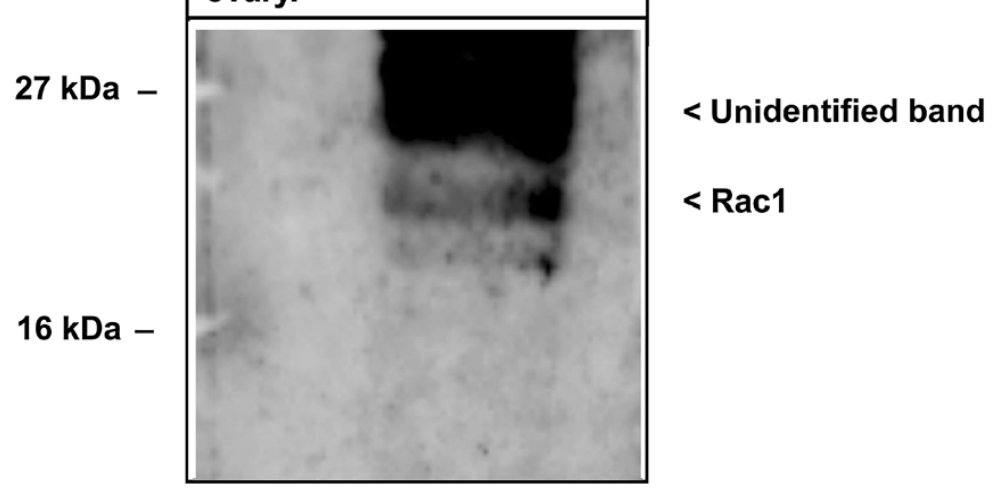

Figure 5 Analysis of Rac1 and Vav interaction in the ovary. Lysate from PCOS ovary was processed for Vav immuno-precipitation followed by immuno-blotting with Rac1 antibody (A); presence of Rac1 in the Vav IP was confirmed by its immuno-blotting (B).

evidence that Caveolin1 regulates Rac1 in the ovarian tissue, particularly in PCOS, we analyzed the expression of Caveolin1. A higher level of caveolin1 in PCOS ovary might have signaled a decrease in Rac1 and Vav levels that favors the development of PCOS phenotype. However, this is purely a speculation and further evidence is required to conclude the exact role of Caveolin1 in pathophysiology of PCOS. Rac1 and Caveolin1 are known to associate during cell proliferation signaling [56]; however, Caveolin1 antagonizing function for Rac1 activity in PCOS pathophysiology needs further validation. Herein, our study can infer that Caveolin1 is dysregulated in the PCOS ovary.
On the basis of our observations, we propose that increased androgens levels result in enhanced conversion of estradiol that initiates a series of events leading to the condition of PCOS. It is perhaps increased $17 \beta-$ estradiol level that results in down regulation of Rac1 and Vav, ultimately, resulting in suspension of follicular development. This leads to arrest of follicular development, and promotes the to accumulation of immature follicles typical to PCOS ovaries. Elevated level of inhibin $B$ is an indicator of repeated recruitment of follicles in the developmental process that is suspended before follicular maturation. How increased $17 \beta$-estradiol levels act on $\mathrm{Rac} / \mathrm{Vav}$ needs to be studied further. 


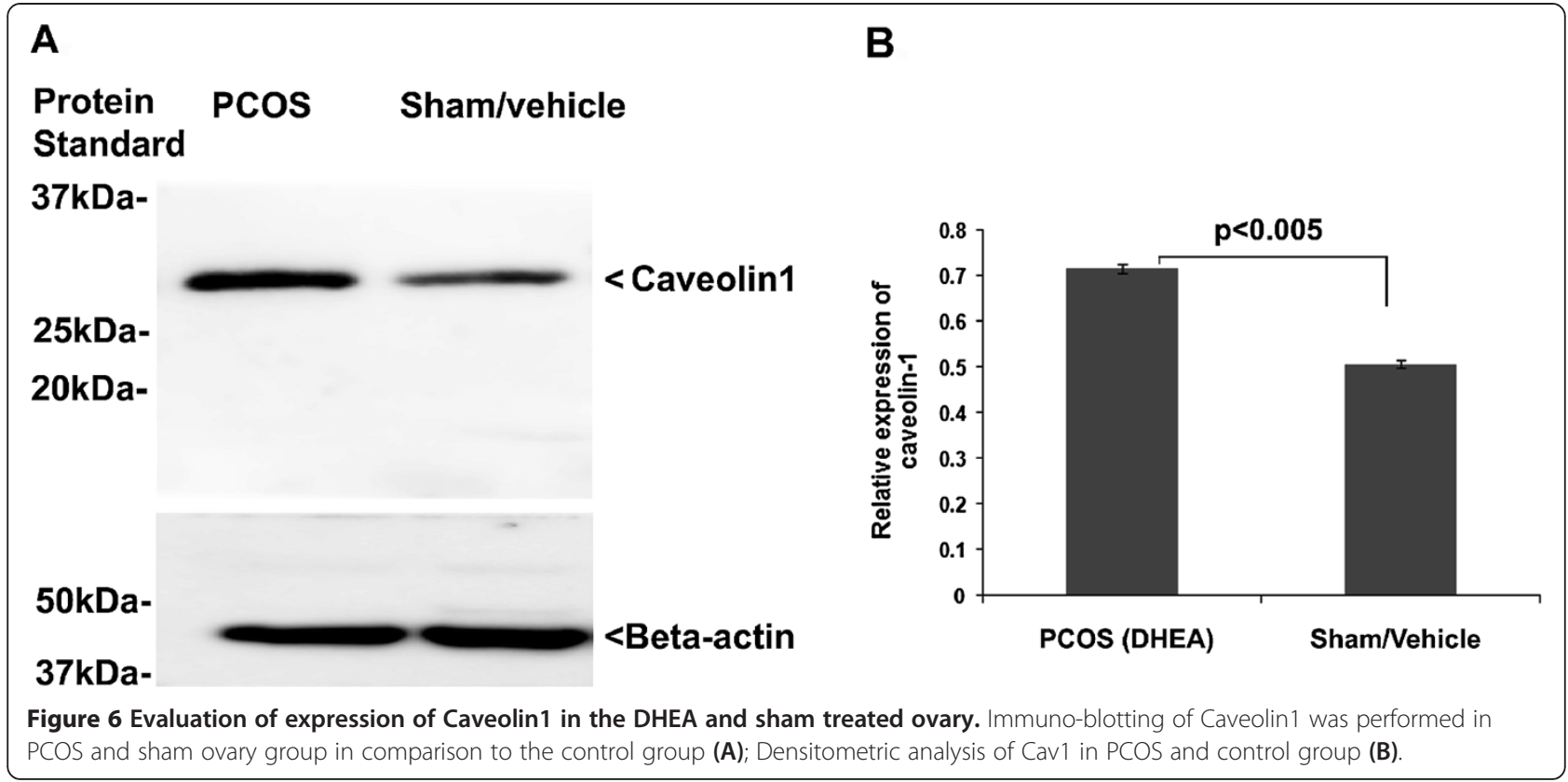

\section{Conclusion}

The results of this study demonstrate for the first time diminished activity of Rac1 and Vav in hyperandrogenized mouse ovaries. Our findings might provide some explanation through small G-protein in the pathogenesis of follicular hyperplasia in PCOS. Altogether, these observations suggest a contribution of elevated estradiol and inhibin B levels due to the DHEA in pathophysiology of PCOS.

\section{Abbreviations}

PCOS: Polycystic ovarian syndrome; DHEA: Dehydroepiandrosterone;

CL: Corpus luteum; FC: Follicle cyst; MS: Metabolic syndrome;

PVDF: Polyvinylidene fluoride; ECL: Enhanced chemiluminescence;

HRP: Horseradish peroxidase; Cat: Catalogue; h: Hour; PFA: Paraformaldehyde; PBS: Phosphate buffer saline; RhoA: Ras homolog gene family member A;

Cdc42: Cell division control protein 42 homolog; Rac: Ras-related C3 botulinum toxin substrate; LH: Luteinizing hormone; IP: Immuno-precipitation.

\section{Competing interests}

The authors declare that they have no competing interests.

\section{Authors' contributions}

VKM carried out PCOS model preparation and development of Rac1, pRac1, Vav and pVav immuno-blot. SC performed Western blotting of Caveolin1, Rac1, pRac1, Vav and pVav along with the 17ß-estradiol assay. VK performed the Rac1 activity assay, tissue paraffin embedding and microtomy. SM did the histological examination of ovarian tissue sections and helped in manuscript drafting. AS performed the immuno-precipitation of Vav, immuno-blotting with Rac1 and Vav along with the inhibin B assay. RS assisted in drafting the manuscript and experimental design. RKJ designed, analyzed the data and finalized the manuscript. All authors read and approved the final manuscript.

\section{Authors' information}

Rajesh Kumar Jha: http://www.cdriindia.org/Rajesh.htm.

Rajender Singh: http://www.cdriindia.org/Rajinder.htm.

\section{Acknowledgments}

Authors would like to acknowledge help of Mr. Geet Kumar Nagar in the histopathology and laboratory facilities of Dr. Anila Dwivedi. CSIR-CDRI manuscript number is 203/2012/RKJ.

\section{Grant support}

This research work received support from BSC0101Council of Scientific and Industrial Research (CSIR), New Delhi India.

\section{Author details}

'Division of Endocrinology, Life Science North 111B/101, CSIR-Central Drug Research Institute, B.S. 10/1, Sector-10, Jankipuram Extension, Sitapur Road, Lucknow 226031, India. ${ }^{2}$ Division of Endocrinology, Life Science South, CSIR-Central Drug Research Institute, B.S. 10/1, Sector-10, Jankipuram Extension, Sitapur Road, Lucknow 226031, India.

Received: 3 September 2013 Accepted: 22 February 2014

Published: 14 March 2014

\section{References}

1. Adhikari D, Liu K: Molecular mechanisms underlying the activation of mammalian primordial follicles. Endocr Rev 2009, 30:438-464.

2. Hirshfield AN: Development of follicles in the mammalian ovary. Int Rev Cytol 1991, 124:43-101. 43-101.

3. McGee EA, Hsueh AJ: Initial and cyclic recruitment of ovarian follicles. Endocr Rev 2000, 21:200-214.

4. Goodarzi MO, Dumesic DA, Chazenbalk G, Azziz R: Polycystic ovary syndrome: etiology, pathogenesis and diagnosis. Nat Rev Endocrinol 2011, 7:219-231.

5. Petrikova J, Lazurova I: Ovarian failure and polycystic ovary syndrome. Autoimmun Rev 2012, 11:A471-A478.

6. Wang S, Alvero R: Racial and ethnic differences in physiology and clinical symptoms of polycystic ovary syndrome. Semin Reprod Med 2013, 31:365-369.

7. Shayya R, Chang RJ: Reproductive endocrinology of adolescent polycystic ovary syndrome. BJOG 2010, 117:150-155.

8. Franks S, Gharani N, Waterworth D, Batty S, White D, Williamson R, McCarthy M The genetic basis of polycystic ovary syndrome. Hum Reprod 1997, 12:2641-2648.

9. Kahsar-Miller M, Azziz R: The development of the polycystic ovary syndrome: family history as a risk factor. Trends Endocrinol Metab 1998 9:55-58. 
10. Bhattacharya SM: Metabolic syndrome in females with polycystic ovary syndrome and International Diabetes Federation criteria. J Obstet Gynaecol Res 2008, 34:62-66.

11. Fan HY, Richards JS: Minireview: physiological and pathological actions of RAS in the ovary. Mol Endocrinol 2010, 24:286-298

12. Lee $M$, Shen B, Schwarzbauer JE, Ahn J, Kwon J: Connections between integrins and Rac GTPase pathways control gonad formation and function in C. elegans. Biochim Biophys Acta 2005, 1723:248-255.

13. Cailleteau L, Estrach S, Thyss R, Boyer L, Doye A, Domange B, Johnsson N, Rubinstein E, Boucheix C, Ebrahimian T, Silvestre JS, Lemichez E, Meneguzzi G, Mettouchi A: alpha2beta1 integrin controls association of Rac with the membrane and triggers quiescence of endothelial cells. J Cell Sci 2010 123:2491-2501.

14. Laufs U, Adam O, Strehlow K, Wassmann S, Konkol C, Laufs K, Schmidt W, Bohm M, Nickenig G: Down-regulation of Rac-1 GTPase by Estrogen. J Biol Chem 2003, 278:5956-5962.

15. Abramovici H, Mojtabaie P, Parks RJ, Zhong XP, Koretzky GA, Topham MK, Gee $\mathrm{SH}$ : Diacylglycerol kinase zeta regulates actin cytoskeleton reorganization through dissociation of Rac1 from RhoGDI. Mol Biol Cell 2009, 20:2049-2059.

16. Sauzeau V, Sevilla MA, Montero MJ, Bustelo XR: The Rho/Rac exchange factor Vav2 controls nitric oxide-dependent responses in mouse vascular smooth muscle cells. J Clin Invest 2010, 120:315-330.

17. Karlsson AB, Maizels ET, Flynn MP, Jones JC, Shelden EA, Bamburg JR, Hunzicker-Dunn M: Luteinizing hormone receptor-stimulated progesterone production by preovulatory granulosa cells requires protein kinase A-dependent activation/dephosphorylation of the actin dynamizing protein cofilin. Mol Endocrinol 2010, 24:1765-1781.

18. Bristow JM, Sellers MH, Majumdar D, Anderson B, Hu L, Webb DJ: The Rho-family GEF Asef2 activates Rac to modulate adhesion and actin dynamics and thereby regulate cell migration. J Cell Sci 2009, 122:4535-4546.

19. Mettouchi A, Klein S, Guo W, Lopez-Lago M, Lemichez E, Westwick JK, Giancotti FG: Integrin-specific activation of Rac controls progression through the $\mathrm{G}(1)$ phase of the cell cycle. Mol Cell 2001, 8:115-127.

20. Garrett TA, Van Buul JD, Burridge K: VEGF-induced Rac1 activation in endothelial cells is regulated by the guanine nucleotide exchange factor Vav2. Exp Cell Res 2007, 313:3285-3297.

21. Vedham $V$, Phee $H$, Coggeshall KM: Vav activation and function as a rac guanine nucleotide exchange factor in macrophage colony-stimulating factor-induced macrophage chemotaxis. Mol Cell Biol 2005, 25:4211-4220.

22. Shyu KG, Chua SK, Wang BW, Kuan P: Mechanism of inhibitory effect of atorvastatin on resistin expression induced by tumor necrosis factor-alpha in macrophages. J Biomed Sci 2009, 16:50. 50.

23. Aoukaty A, Tan R: Role for glycogen synthase kinase-3 in NK cell cytotoxicity and X-linked lymphoproliferative disease. J Immunol 2005, 174:4551-4558.

24. Crespo P, Schuebel KE, Ostrom AA, Gutkind JS, Bustelo XR: Phosphotyrosine-dependent activation of Rac-1 GDP/GTP exchange by the vav proto-oncogene product. Nature 1997, 385:169-172.

25. Elia E, Sander V, Luchetti CG, Solano ME, Di GG, Gonzalez C, Motta AB: The mechanisms involved in the action of metformin in regulating ovarian function in hyperandrogenized mice. Mol Hum Reprod 2006, 12:475-481.

26. Luchetti CG, Solano ME, Sander V, Arcos ML, Gonzalez C, Di GG, Chiocchio S, Cremaschi G, Motta AB: Effects of dehydroepiandrosterone on ovarian cystogenesis and immune function. J Reprod Immunol 2004, 64:59-74.

27. Sander V, Luchetti CG, Solano ME, Elia E, Di GG, Gonzalez C, Motta AB: Role of the $\mathrm{N}, \mathrm{N}$-dimethylbiguanide metformin in the treatment of female prepuberal $\mathrm{BALB} / \mathrm{c}$ mice hyperandrogenized with dehydroepiandrosterone. Reproduction 2006, 131:591-602.

28. Zhu JQ, Zhu L, Liang XW, Xing FQ, Schatten H, Sun QY: Demethylation of LHR in dehydroepiandrosterone-induced mouse model of polycystic ovary syndrome. Mol Hum Reprod 2010, 16:260-266.

29. Anderson E, Lee MT, Lee GY: Cystogenesis of the ovarian antral follicle of the rat: ultrastructural changes and hormonal profile following the administration of dehydroepiandrosterone. Anat Rec 1992, 234:359-382.

30. Henmi H, Endo T, Nagasawa K, Hayashi T, Chida M, Akutagawa N, Iwasaki M, Kitajima Y, Kiya T, Nishikawa A, Manase K, Kudo R: Lysyl oxidase and MMP-2 expression in dehydroepiandrosterone-induced polycystic ovary in rats. Biol Reprod 2001, 64:157-162.
31. Lee GY, Croop JM, Anderson E: Multidrug resistance gene expression correlates with progesterone production in dehydroepiandrosterone-induced polycystic and equine chorionic gonadotropin-stimulated ovaries of prepubertal rats. Biol Reprod 1998, 58:330-337.

32. Maurya VK, Jha RK, Kumar V, Joshi A, Chadchan S, Mohan JJ, Laloraya M: Transforming growth factor-beta 1 (TGF-B1) liberation from its latent complex during embryo implantation and its regulation by estradiol in mouse. Biol Reprod 2013, 89:84

33. Hayashida T, Jones JC, Lee CK, Schnaper HW: Loss of beta1-integrin enhances TGF-beta1-induced collagen expression in epithelial cells via increased alphavbeta3-integrin and Rac1 activity. J Biol Chem 2010, 285:30741-30751.

34. Laemmli UK: Cleavage of structural proteins during the assembly of the head of bacteriophage T4. Nature 1970, 227:680-685.

35. Towbin H, Staehelin T, Gordon J: Electrophoretic transfer of proteins from polyacrylamide gels to nitrocellulose sheets: procedure and some applications. 1979. Biotechnology 1992, 24:145-149. 145-9.

36. Eldar-Geva T, Robertson DM, Cahir N, Groome N, Gabbe MP, Maclachlan V, Healy DL: Relationship between serum inhibin A and B and ovarian follicle development after a daily fixed dose administration of recombinant follicle-stimulating hormone. J Clin Endocrinol Metab 2000, 85:607-613

37. Anderson RA, Groome NP, Baird DT: Inhibin A and inhibin B in women with polycystic ovarian syndrome during treatment with $\mathrm{FSH}$ to induce mono-ovulation. Clin Endocrinol (Oxf) 1998, 48:577-584.

38. Dafopoulos K, Venetis C, Messini Cl, Pournaras S, Anifandis G, Garas A, Messinis IE: Inhibin secretion in women with the polycystic ovary syndrome before and after treatment with progesterone. Reprod Biol Endocrinol 2011, 9:59. doi: 10.1186/1477-7827-9-59.: 59.

39. Lockwood GM, Muttukrishna S, Groome NP, Matthews DR, Ledger WL: Mid-follicular phase pulses of inhibin B are absent in polycystic ovarian syndrome and are initiated by successful laparoscopic ovarian diathermy: a possible mechanism regulating emergence of the dominant follicle. J Clin Endocrinol Metab 1998, 83:1730-1735.

40. Tong $H$, Zhao B, Shi $H, B a X$, Wang $X$, Jiang $Y$, Zeng $X$ : c-Abl tyrosine kinase plays a critical role in beta2 integrin-dependent neutrophil migration by regulating Vav1 activity. J Leukoc Biol 2013, 93:611-622.

41. Minshall RD, Sessa WC, Stan RV, Anderson RG, Malik AB: Caveolin regulation of endothelial function. Am J Physiol Lung Cell Mol Physiol 2003, 285:L1179-L1183.

42. Bristol-Gould SK, Kreeger PK, Selkirk CG, Kilen SM, Mayo KE, Shea LD, Woodruff TK: Fate of the initial follicle pool: empirical and mathematical evidence supporting its sufficiency for adult fertility. Dev Biol 2006, 298:149-154.

43. Faddy MJ, Telfer E, Gosden RG: The kinetics of pre-antral follicle development in ovaries of CBA/Ca mice during the first 14 weeks of life. Cell Tissue Kinet 1987, 20:551-560.

44. Fan HY, Liu Z, Mullany LK, Richards JS: Consequences of RAS and MAPK activation in the ovary: the good, the bad and the ugly. Mol Cell Endocrinol 2012, 356:74-79.

45. Hackney JF, Pucci C, Naes E, Dobens L: Ras signaling modulates activity of the ecdysone receptor EcR during cell migration in the Drosophila ovary. Dev Dyn 2007, 236:1213-1226.

46. Lee T, Montell DJ: Multiple Ras signals pattern the Drosophila ovarian follicle cells. Dev Biol 1997, 185:25-33.

47. Yodoi R, Tamba S, Morimoto K, Segi-Nishida E, Nishihara M, Ichikawa A Narumiya S, Sugimoto $Y$ : RhoA/Rho kinase signaling in the cumulus mediates extracellular matrix assembly. Endocrinology 2009, 150:3345-3352.

48. Vlachos S, Harden N: Genetic evidence for antagonism between Pak protein kinase and Rho1 small GTPase signaling in regulation of the actin cytoskeleton during Drosophila oogenesis. Genetics 2011, 187:501-512.

49. Dunaif A, Thomas A: Current concepts in the polycystic ovary syndrome. Annu Rev Med 2001, 52:401-419. 401-19.

50. Ehrmann DA: Polycystic ovary syndrome. N Engl J Med 2005, 352:1223-1236.

51. Norman RJ, Dewailly D, Legro RS, Hickey TE: Polycystic ovary syndrome. Lancet 2007, 370:685-697.

52. Aragno M, Brignardello E, Tamagno E, Gatto V, Danni O, Boccuzzi G Dehydroepiandrosterone administration prevents the oxidative damage induced by acute hyperglycemia in rats. J Endocrinol 1997, 155:233-240. 
53. Alsamarai S, Adams JM, Murphy MK, Post MD, Hayden DL, Hall JE, Welt CK: Criteria for polycystic ovarian morphology in polycystic ovary syndrome as a function of age. J Clin Endocrinol Metab 2009, 94:4961-4970.

54. Citterio C, Menacho-Marquez M, Garcia-Escudero R, Larive RM, Barreiro O, Sanchez-Madrid F, Paramio JM, Bustelo XR: The rho exchange factors vav2 and vav3 control a lung metastasis-specific transcriptional program in breast cancer cells. Sci Signal 2012, 5:ra71.

55. Nethe M, Hordijk PL: The role of ubiquitylation and degradation in RhoGTPase signalling. J Cell Sci 2010, 123:4011-4018.

56. Cerezo A, Guadamillas MC, Goetz JG, Sanchez-Perales S, Klein E, Assoian RK, del Pozo MA: The absence of caveolin-1 increases proliferation and anchorage- independent growth by a Rac-dependent, Erk-independent mechanism. Mol Cell Biol 2009, 29:5046-5059.

doi:10.1186/1757-2215-7-32

Cite this article as: Maurya et al.: Expression and activity of Rac1 is negatively affected in the dehydroepiandrosterone induced polycystic ovary of mouse. Journal of Ovarian Research 2014 7:32.

\section{Submit your next manuscript to BioMed Central and take full advantage of:}

- Convenient online submission

- Thorough peer review

- No space constraints or color figure charges

- Immediate publication on acceptance

- Inclusion in PubMed, CAS, Scopus and Google Scholar

- Research which is freely available for redistribution 